\title{
Persistent places: An approach to the interpretation of assemblage variation in deflated surface stone artefact distributions from western New South Wales, Australia
}

Justin Shiner

\author{
Archaeology Program \\ La Trobe University \\ Victoria \\ Australia 3086
}

\begin{abstract}
The construction of models of past settlement systems in the Australian arid zone are based on serious misunderstandings of the formation of deflated archaeological deposits. This in turn leads to the application of inappropriate interpretative frameworks that often ignore chronological contexts and assume that spatially separate deposits are contemporary, and demonstrate consistency in human behaviour through time. This denies archaeologists the opportunity to explore the temporal aspects of deflated records, both in terms of chronology and the management of stone artefact manufacture across space and through time. Radiocarbon determinations from heat-retainer hearths and stone artefact assemblage data from the Pine Point/Langwell area of western New South Wales (NSW) near Broken Hill are used to demonstrate the concept of archaeological deposits as persistent places across the landscape. This combined with an analysis of variability in stone artefact assemblage composition provides an alternative framework to synchronic models.
\end{abstract}

Keywords: deflated deposits, persistent place, chronology

\section{Introduction}

Heat-retainer hearths and stone artefacts dominate the surface archaeological record of semi-arid western New South Wales. These most frequently occur as deflated and spatially extensive distributions of varying density with occasional hearths. They typically lack clear and readily definable boundaries. The deflation of the artefacts has resulted in the loss of vertical integrity and relative chronological relationships between artefacts. Consequently, it is difficult to group artefacts into assemblages for analysis. The definition of assemblages in these contexts rarely, if ever, has anything to do with fine-scale temporal and 
spatial behavioural patterns. Rather, assemblages are often defined according to similarities in landscape context, broader temporal context or geomorphologic boundaries (Holdaway et al. 2000). In this sense assemblages are collections of artefacts that may represent multiple behavioural episodes rather than discrete events. The formational characteristics of these deposits pose numerous methodological and theoretical challenges for archaeologists interested in the study and interpretation of the surface archaeological record from the Australian arid zone.

Surface deposits contain numerous artefacts often representing multiple stages of core reduction, tool manufacture and discard. Based upon assemblage composition alone it is difficult to classify these deposits into distinct site types that correspond with the perceived function of the location within a settlement system. For instance, based on ethnographic observation Cane (1984) argued that assemblages with high proportions of scrapers represented woodworking locations. But Cane's own investigations demonstrated that high proportions of scrapers were also recorded at sites where ethnographic information indicated that woodworking was not the primary activity.

The raw material types present reflect the exploitation of both local and non-local sources. Where chronological contexts have been established (Holdaway et al. 2002, 2005; Shiner 2004), these indicate multiple episodes of hearth construction. Although it is impossible to establish direct temporal relationships between any single artefact and hearth, the multiple age determinations from the hearths point to numerous episodes of occupation during which artefacts may have been discarded. From this perspective the deflated surface deposits of western NSW are palimpsests of material that may have accumulated from an unknown number of behavioural events. These events may be spread over several hundred or more years. Therefore, these deposits suggest the repeated use of place through time and not a single one-off behavioural event.

These factors mean that synchronic interpretations of site function within a single land-use model is not an appropriate interpretative framework for deflated surface deposits. Interpretations of the record that do not consider the temporal dimension of the formation of surface deposits ignore the possibility that the artefacts found on a common eroded surface may have been discarded at different times during the past. The behavioural context under which these were discarded may also have varied. This leads to questions regarding the nature of these occupations and the factors that may result in the reuse of places.

Schlanger (1992) used the term 'persistent place' to describe those areas of the landscape that are the focus of repeated activity through time. Persistent places fall into two categories. The first is associated with features of the natural environment that may attract human occupation, e.g. swamps, waterholes, rock outcrops etc. The second reflects the type of materials and features that humans create in the occupation of a location. In the case of western NSW these might be stone arrangements, heat-retainer hearths or raw material caches. Once established these features will structure the future use of the location, either through reuse or avoidance (see also Fletcher 1995). The role of features may also change during subsequent occupations. With this the duration and character of occupation may also vary through time. Another factor to consider is that the preserved pattern of site distribution and assemblage composition might not be representative of the prehistoric pattern of human activity. As Waters and Kuehn (1996) note, landscapes are dynamic and continually changing, sites are destroyed over time and this fragments the record of cultural systems. This is particularly true in western NSW where significant landscape change has occurred with the arrival of pastoral and mining land use (Fanning 2002).

Even though persistent places may not attract permanent settlement, they may attract long-term episodic use. The notion of persistent place is useful for investigating the long-term histories of individual locations because it acknowledges the role of multiple behavioural events in the accumulation of the archaeological record. Within this context, assemblage accumulation represents multiple processes that may have very different temporal trajectories, rather than the result of a synchronic functionalenvironmental relationship between discard and place use. The composition of assemblages and the spatial structure of artefact distributions reflect the long-term repeated use of locations. The notion of persistent places is a useful framework for investigating the formation of deflated surface archaeological distributions across western NSW. 


\section{The surface archaeological record of Pine Point and Langwell}

Pine Point and Langwell are sheep grazing properties approximately 50 kilometres south of Broken Hill (Figure 1). The properties straddle the transitional zone between the foothills of the Barrier Range in the north to the alluvial sand plain of the Murray-Darling in the south. Following the methods of Holdaway et al. (2000), land system classifications were used to divide the study area into four separate areas. Aerial photographs were then used to identify locations within each of the land systems that were likely to contain surface archaeological deposits. Extensive scalding, proximity to drainage systems and topography were the key criteria used to identify these locations. Each identified location was then ground checked to assess the potential for detailed recording.

In common with other areas of western NSW (e.g. Holdaway et al. 2000; Holdaway et al. 2004), surface stone artefact distributions across Pine Point and Langwell have lost their vertical integrity through the erosion of topsoil resulting in the deflation of the artefacts onto the scalded A2 soil horizon. Hearths appear as either clustered or dispersed distributions of stone and clay heat retainers that represent the base of the hearth pit. In some instances the heat retainers serve to 'cap' charcoal concentrated in sediments on the hard baked bottom of the hearth fire pit. To be selected a location had to have an extensive distribution of stone artefacts and heat-retainer hearths that were likely to retain charcoal for radiometric analysis.

Ten locations meeting these criteria were selected for investigation. Preliminary artefact recording and hearth survey were conducted at each location. Following this initial phase of investigation further recording was restricted to four main locations where charcoal-bearing hearths and extensive stone artefact scatters were abundant (Table 1). Two of these, CN1 and $\mathrm{CN} 3$, are in the Conservation/ Fowlers land system and are situated on an alluvial terrace adjacent to Pine Creek, the

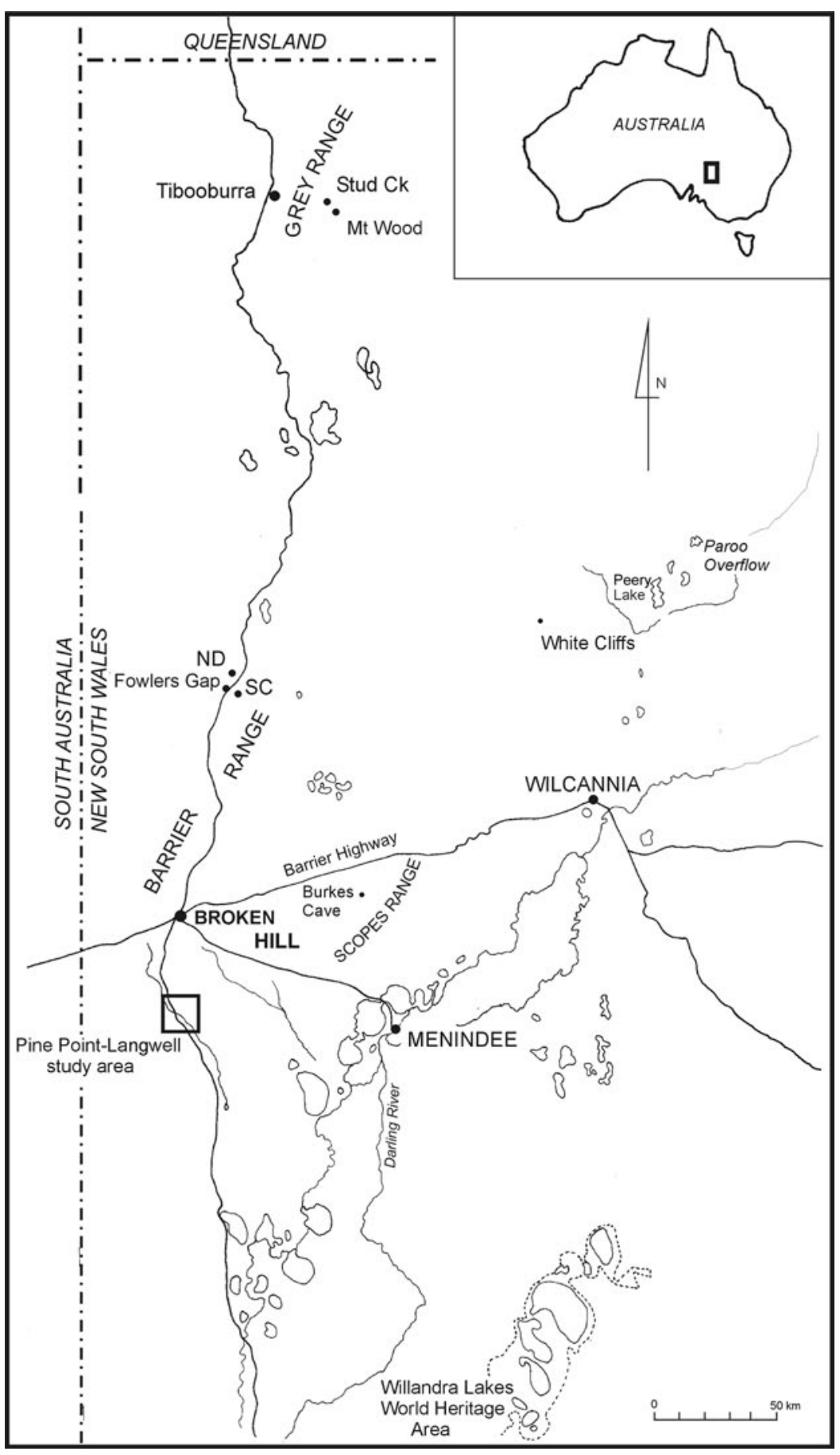

Figure 1. Location of the Pine Point/Langwell study area and other locations mentioned in the text. 
largest drainage channel in the study area. The other two, KZ1 and KZ2, are in the Kars land system and are adjacent to Rantyga Creek, the second largest drainage channel in the study area. KZ1 covers an alluvial terrace and distal flood plain on both sides of Rantyga Creek. KZ2 is situated on a scalded sandy rise on the northern side of Rantyga Creek. The locations are all situated within the immediate vicinity of the confluence of Rantyga Creek with the larger Pine Creek. The distance from the furthest two locations KZ1 and CN3 is four kilometres.

\begin{tabular}{|c|c|c|c|c|c|}
\hline Land System & $\begin{array}{l}\text { Sampling } \\
\text { Location }\end{array}$ & Description & $\begin{array}{l}\text { Sampling } \\
\text { Area } \mathrm{m}^{2}\end{array}$ & Artefacts & Hearths \\
\hline $\begin{array}{l}\text { Conservation/ } \\
\text { Fowlers }\end{array}$ & CN1 & $\begin{array}{l}\text { Discontinuous hardpan } \\
\text { scald situated on top of } \\
\text { a major terrace of Pine } \\
\text { Creek, approximately } \\
600 \text { metres downstream } \\
\text { of the Pine Creek-Rantyga } \\
\text { Creek confluence. }\end{array}$ & 19355 & 8788 & $\begin{array}{l}\text { CNH7, } \\
\text { CNH23 } \\
\text { to } \\
\text { CNH25, } \\
\text { CNH42, } \\
\text { CNH55 }\end{array}$ \\
\hline $\begin{array}{l}\text { Conservation/ } \\
\text { Fowlers }\end{array}$ & $\mathrm{CN} 3$ & $\begin{array}{l}\text { Extensive hardpan scald } \\
\text { situated on top of terrace of } \\
\text { Pine Creek, starting } 1.2 \\
\text { kilometres metres } \\
\text { downstream of the Pine } \\
\text { Creek-Rantyga Creek } \\
\text { confluence. }\end{array}$ & 12813 & 4904 & $\begin{array}{l}\text { CNH32 } \\
\text { to } \\
\text { CNH36 } \\
\text { and } \\
\text { CNH56 }\end{array}$ \\
\hline Kars & KZ1 & $\begin{array}{l}\text { Series of hardpan scalds on } \\
\text { distal flood plain of Rantyga } \\
\text { Creek, approximately three } \\
\text { kilometres upstream of } \\
\text { confluence with Pine Creek. }\end{array}$ & 11795 & 3419 & $\begin{array}{l}\text { KZ1H2, } \\
\text { KZ1H3, } \\
\text { KZ1H7 }\end{array}$ \\
\hline Kars & KZ2 & $\begin{array}{l}\text { Series of hardpan exposures } \\
\text { on top of a sandy rise and } \\
\text { distal flood plain adjacent } \\
\text { to Rantyga Creek, } \\
\text { approximately } 1.5 \text { kilometres } \\
\text { upstream of confluence } \\
\text { with Pine Creek. }\end{array}$ & 7203 & 11192 & KZ2H25 \\
\hline
\end{tabular}

Table 1. Characteristics of the archaeological sampling areas.

The four locations chosen for study are not discrete and bounded sites. Rather they represent areas of high ground exposure (resulting from erosion and a lack of vegetation) where extensive distributions of stone artefacts and hearths are visible. The issue of site definition has been widely discussed in such contexts (e.g. Ebert 1992; Thomas 1975). In western NSW, Holdaway et al. (1998) suggested that site boundaries are difficult if not impossible to define and that archaeologists should consider factors relating to the geomorphic context of artefact distributions when attempting to define assemblages. The same approach is adopted here. The Pine Point/Langwell assemblages were defined according to their geomorphic context. In the case of $\mathrm{CN} 1$ and $\mathrm{CN} 3$ this was the major terrace running parallel to the northern bank of Pine Creek. For KZ1 and KZ2, artefact recording was confined to the hard pan surfaces on the fringe of the distal flood plain. The assemblages represent samples of larger artefact distributions. 
The proximity of the artefact assemblages to the Pine Creek-Rantyga Creek confluence suggested the possibility that the chronological record would indicate multiple phases of occupation. Although significant environmental change has occurred with pastoral land use, the creek confluence is a major landscape feature that appeared to be a focus of past human activity (numerous stone artefacts and hearths). It is possible that the four locations may represent persistent places with characteristics similar to those identified by Schlanger. To investigate this required the establishment of an occupational chronology and the analysis of stone artefact assemblage composition.

\section{Chronological context}

The remains of 122 heat-retainer hearths were recorded during intensive pedestrian survey of the Pine Creek-Rantyga Creek confluence. Information on the excavation and recording of the hearths has been published elsewhere (Holdaway et al. 2005), and is briefly summarised here. Hearths were classified into three groups according to their relative degree of preservation. Of those with partially exposed and clustered heat retainers, 30 were selected for excavation, based on their spatial proximity to the stone artefact recording areas. The excavated hearths consisted of a sandy matrix with a cluster of heat retainers and varied amounts of mostly fragmented charcoal. No structural evidence of hearth reuse or multiple lenses of charcoal were found.

Sufficient charcoal for radiocarbon determinations was recovered from 16 hearths. The hearths are distributed along the alluvial gullies of Rantyga and Pine Creeks. Hearths KZ1 H2, H3, and H7 are associated with the KZ1 location. KZ2 H25 is associated with KZ2 location. CN H7, H23, H24, H25, H42 and H55 are associated with the CN1 location. Hearths CN H32, H33, H34, H35, H36 and H56 are associated with the CN3 location. In Table 2 the determinations are listed in chronological order from youngest to oldest.

\begin{tabular}{|c|c|c|c|c|}
\hline $\begin{array}{l}\text { Lab } \\
\text { Number }\end{array}$ & Result (year BP) & $\delta \mathrm{C} 13$ & $\begin{array}{l}\text { Calibrated } 2 \sigma \text { ages } \\
\text { (y BP (probability) }\end{array}$ & $\begin{array}{l}\text { Hearth } \\
\text { ID }\end{array}$ \\
\hline Wk-9994 & $261 \pm 49$ & $-23.8 \pm 0.2$ & $\begin{array}{l}160-166(0.053) \\
287-315(0.514) \\
408-420(0.107)\end{array}$ & CN H 42 \\
\hline Wk-12322 & $458 \pm 58$ & $-24.1 \pm 0.2$ & $463-545$ (0.682) & CN H 34 \\
\hline Wk-12323 & $481 \pm 55$ & $-23.5 \pm 0.2$ & $477-534(0.686)$ & CN H 35 \\
\hline Wk-12324 & $516 \pm 52$ & $-23.0 \pm 0.2$ & $\begin{array}{l}510-554(0.572) \\
609-620(0.102)\end{array}$ & CN H 36 \\
\hline Wk-12326 & $584 \pm 46$ & $-22.2 \pm 0.2$ & $\begin{array}{l}544-564(0.212) \\
587-590(0.025) \\
599-645(0.47)\end{array}$ & KZ2 H 25 \\
\hline Wk-12325 & $771 \pm 46$ & $-24.6 \pm 0.2$ & $\begin{array}{l}737-795(0.344) \\
812-829(0.098) \\
862-906(0.235)\end{array}$ & CN H 56 \\
\hline Wk-9995 & $848 \pm 69$ & $-23.4 \pm 0.2$ & $\begin{array}{l}687-794(0.542) \\
813-827(0.057) \\
866-886(0.078)\end{array}$ & KZ1 H 2 \\
\hline Wk-10282 & $886 \pm 47$ & $-23.9 \pm 0.2$ & $\begin{array}{l}737-795(0.344) \\
812-829(0.098) \\
862-906(0.235)\end{array}$ & CN H 55 \\
\hline
\end{tabular}




\begin{tabular}{|c|c|c|c|c|}
\hline $\begin{array}{l}\text { Lab } \\
\text { Number }\end{array}$ & Result (year BP) & $\delta \mathrm{C} 13$ & $\begin{array}{l}\text { Calibrated } 2 \sigma \text { ages } \\
\text { (y BP (probability) }\end{array}$ & $\begin{array}{l}\text { Hearth } \\
\text { ID }\end{array}$ \\
\hline Wk-10280 & $910 \pm 52$ & $-23.0 \pm 0.2$ & $\begin{array}{l}765-779(0.071) \\
787-798(0.059) \\
809-839(0.162) \\
842-912(0.384)\end{array}$ & CN H 23 \\
\hline Wk-10832 & $959 \pm 51$ & $-22.1 \pm 0.2$ & $\begin{array}{l}793-814(0.137) \\
826-867(0.26) \\
884-929(0.274)\end{array}$ & KZ1 H 7 \\
\hline Wk-12320 & $967 \pm 62$ & $-21.9 \pm 0.2$ & $\begin{array}{l}794-814(0.133) \\
826-867(0.257) \\
884-931(0.287)\end{array}$ & CN H 25 \\
\hline Wk-12319 & $1002 \pm 48$ & $-24.5 \pm 0.2$ & $\begin{array}{l}797-809(0.094) \\
835-848(0.075) \\
911-963(0.517)\end{array}$ & CN H 24 \\
\hline Wk-12321 & $1247 \pm 56$ & $-23.9 \pm 0.2$ & $\begin{array}{l}1092-1108(0.071) \\
1126-1160(0.158) \\
1169-1193(0.132) \\
1197-1241(0.259) \\
1245-1261(0.082)\end{array}$ & CN H 33 \\
\hline Wk-10281 & $1653 \pm 52$ & $-23.2 \pm 0.2$ & $\begin{array}{l}1421-1430(0.028) \\
1489-1497(0.024) \\
1515-1613(0.553) \\
1623-1625(0.006) \\
1674-1689(0.061)\end{array}$ & CN H 32 \\
\hline Wk-9993 & $1747 \pm 76$ & $-23.5 \pm 0.2$ & $1550-1734(0.678)$ & CN H 7 \\
\hline Wk-10831 & $2004 \pm 73$ & $-23.2 \pm 0.2$ & $1871-2044(0.678)$ & KZ1 H 3 \\
\hline
\end{tabular}

Table 2. Radiocarbon determinations from Pine Point/Langwell (after Holdaway et al. 2005).

A full analysis of the Pine Point/Langwell radiocarbon determinations is presented in Holdaway et al. (2005), the feature of which is a Bayesian analysis of temporal patterning within the total pool of 16 determinations. This indicated that, rather than forming a continuous sequence, the determinations cluster into five main phases of hearth construction. The oldest is a single determination from KZ1 H3 at approximately $2000 \mathrm{cal} \mathrm{BP}$. The second group consists of two hearths with determinations between 1500 and $1700 \mathrm{cal} \mathrm{BP}$. The third group is one hearth with a determination between 1050 and $1300 \mathrm{cal} \mathrm{BP}$. Seven determinations make up the fourth group, with determinations spanning 750 to $950 \mathrm{cal}$ BP. The fifth and final group consists of five determinations spanning 550 to 350 cal BP. Together the radiocarbon determinations from the 16 hearths indicate a chronology of late Holocene occupation across the four study localities and a temporal framework for the investigation of stone artefact assemblage formation.

\section{Measuring the intensity of raw material utilisation}

Artefact assemblages usually consist of both short and long use-life artefacts. Short use-life artefacts are those that have performed little or no work (Shott 1989, 1995). Characteristically, these are unretouched flakes and other debitage produced during core reduction and tool manufacture (Holdaway et al. 2004; Shiner et al. 2005). These have a high probability of discard and the majority of assemblages are composed 
of large numbers of these items. Long use-life artefacts mainly consist of retouched tools that can be ranked according to the degree to which they have been resharpened. The least resharpened tools are utilised flakes, which exhibit non-invasive retouch. These are usually flakes that have been used to perform work without prior edge modification. More heavily resharpened tools consist of denticulates, notches, scrapers and burren and tula adzes that have been deliberately modified before use. The most heavily resharpened item in arid zone assemblages is the tula adze, which following repeated resharpening is often, but not always, discarded as a worked-out 'slug' (Gould 1980; Hayden 1979, Holdaway et al. 2004). In some cases, the use-life of these items may exceed the occupation duration of a single location.

The discard of artefacts is a time-dependent process and the composition of assemblages is an indirect result of occupation duration (Bamforth and Becker 2000). As occupation becomes longer there is a greater probability that long use-life artefacts will be created and discarded (Holdaway et al. 2000).

Differences in the intensity of raw material reduction offer one promising approach to the investigation of assemblage composition because increased occupation duration may lead to the more intensive utilisation of material available within the immediate context of an occupied location (Dibble 1988; Dibble and Rolland 1992; Elston 1990). This can be investigated through the study of assemblage composition. Assemblages that exhibit high flake-to-core ratios, a low proportion of cortical artefacts, a decrease in flake and core size, and the presence of heavily worked tools and cores reflect more intensive reduction of raw materials (Dibble et al. 1995). These characteristics, combined with the concept of timedependent artefact discard, provide a method for investigating the intensity of place use from stone artefact assemblages, without recourse to functional interpretations.

\section{Raw material utilisation}

In common with surface stone artefact assemblages from other areas of western NSW (Holdaway et al. 2000; Shiner et al. 2005; Witter 1992), the Pine Point/Langwell assemblages are dominated by quartz and silcrete. There are clear differences in the proportion of raw materials between the two $\mathrm{CN}$ and the two KZ assemblages (Table 3). All four assemblages are dominated by quartz, but the proportion of quartz in the $\mathrm{CN}$ assemblages is considerably greater than in the $\mathrm{KZ}$ assemblages. Approximately $80 \%$ of artefacts in the $\mathrm{CN} 1$ and $\mathrm{CN} 3$ assemblages are made from quartz. There are two types of silcrete - clast (quartz grains present in the matrix) and non-clast (quartz grains rare or absent in the matrix). The two types of silcrete combined account for $16.3 \%$ of raw materials at $\mathrm{CN} 1$ and $14.1 \%$ at $\mathrm{CN} 3$.

\begin{tabular}{|lllll|}
\hline Core Type & CN1 & CN3 & KZ1 & KZ2 \\
\hline Clast & $1091(12.4)$ & $544(11.1)$ & $936(27.4)$ & $3526(31.5)$ \\
\hline Non-clast & $347(3.9)$ & $145(3)$ & $248(7.3)$ & $575(5.1)$ \\
\hline Quartz & $7228(82.2)$ & $4107(83.7)$ & $2135(62.4)$ & $6895(61.6)$ \\
\hline Other & $122(1.4)$ & $108(2.2)$ & $100(2.9)$ & $196(1.7)$ \\
\hline Total & $8788(100)$ & $4904(100)$ & 3419 & $11192(100)$ \\
\hline
\end{tabular}

Table 3. Raw material number and percentage (in parentheses) per assemblage.

The KZ1 and KZ2 assemblages demonstrate a pattern of raw material abundance different from the $\mathrm{CN} 1$ and $\mathrm{CN} 3$ assemblages. Quartz accounts for $62.4 \%$ of raw materials at KZ1 and $61.6 \%$ at KZ2. The two types of silcrete combined account for $34.7 \%$ at KZ1 and 36.6\% at KZ2. Therefore, the proportion of silcrete in the $\mathrm{KZ}$ assemblages is considerably greater than in the $\mathrm{CN}$ assemblages. As with the $\mathrm{CN}$ assemblages, silcrete is dominated by clast material. The proportion of non-clast silcrete is slightly greater at KZ1 $(7.3 \%)$ compared to KZ2 (5.1\%). The category 'other materials' includes crystal quartz, chert, 
hornfels, ironstone, quartzite, sandstone and schist, and these make up only a small percentage of raw material.

Differences in raw material access are likely to account for some of the variability in the relative proportions of raw materials between the assemblages. Quartz is available as fist-sized cobbles in creek beds and as gibber pavements within immediate vicinity of all the assemblages, and is classified as a local raw material. Clast silcrete outcrops with evidence of human use occur in the low hills approximately six kilometres north of Pine Creek. The characteristics of one of these assemblages are analysed in Shiner (2006). No sources of non-clast silcrete were identified in the study area. Both types of silcrete are regarded as a non-local raw material because sources of each are not available within the immediate vicinity of any of the assemblages. The two KZ assemblages contain the highest proportions of silcrete, and are located two to three kilometres in a straight line from the silcrete outcrops. The $\mathrm{CN}$ assemblages are located five to six kilometres in a straight line from the silcrete outcrops.

Access to raw materials is clearly an important factor in assemblage variability. Exposure of raw material sources is unlikely to have been a limiting factor because the landscapes of Pine Point and Langwell are primarily erosion dominated, and outcrops and gibber pavements are widely distributed. Alternatively, access to raw material sources is likely to have varied with factors associated with the duration of occupation, and mobility reduction as occupation duration increases. The role of these factors can be assessed through the comparison of key technological indices related to the intensity of raw material reduction. These methods have been widely used in both Australia (Holdaway et al. 2000, 2004; Shiner 2004; Shiner et al. 2005; Veth 1993) and elsewhere (Bamforth and Becker 2000; Dibble 1995) and are discussed in the following section.

\section{Core form}

Core form is indicative of the techniques used to reduce nodules. For example, non-specialised core forms with platforms flaked from only one direction (unifacial) and with only one or two negative flake scars (test), suggest non-intensive core reduction strategies. Those with platforms flaked from two or more directions (bifacial and multi-platform) indicate core rotation and a concern with extending the reduction life of nodules. There is some possibility that sample size is influencing the proportion of different core forms represented in each assemblage. For example, the largest assemblage, KZ2, also generally has the greatest number of different core forms. Despite this, the number of artefacts in each assemblage is sufficiently large to allow confidence that the patterns are also representative of behavioural characteristics e.g. occupation duration, rather than sample size alone.

The proportion of different clast silcrete core forms in each assemblage is presented in Table 4. Eight different core forms are represented, with eight at KZ2, five at KZ1, four at CN1 and three at CN3. Microblade, nuclear-tool and radial core forms were only recorded at KZ2, while flake-blank forms were confined to KZ1 and KZ2. Proportions of test core forms vary from $9.4 \%$ at CN1 followed by $3 \%$ at KZ1 and $2.6 \%$ at KZ2. They are not represented at CN3.

\begin{tabular}{|llllc|}
\hline Core Type & CN1 & CN3 & KZ1 & KZ2 \\
\hline Bifacial & $4(12.5)$ & $2(9.5)$ & $6(18.2)$ & $31(27)$ \\
\hline Flake blank & & & $1(3)$ & $8(7)$ \\
\hline Microblade & & & $9(27.3)$ & $1(0.9)$ \\
\hline Multiple & $1(3.1)$ & $4(19)$ & & $1(4.3)$ \\
\hline Nuclear tool & & & $1(3)$ & $3(2.6)$ \\
\hline Radial & $3(9.4)$ & $15(71.5)$ & $16(48.5)$ & $3(2.6)$ \\
\hline Test & $24(75)$ & $21(100)$ & $33(100)$ & $115(100)$ \\
\hline Unifacial & $32(100)$ & & \\
\hline Total & & & & \\
\hline
\end{tabular}

Table 4. Frequency and proportion of clast silcrete core types per assemblage. 
Unifacial cores are the single most common clast silcrete core form in all of the assemblages, varying from $75 \%$ at $\mathrm{CN} 1,71.5 \%$ at $\mathrm{CN} 3,54.8 \%$ at $\mathrm{KZ2}$ and $48.5 \%$ at $\mathrm{KZ1}$. At $\mathrm{KZ1}$ the combined proportion of rotated forms $(45.5 \%)$ is smaller than that of unifacial forms $(48.5 \%)$, although this is still a relatively high proportion of rotated forms and is much greater than that for the other three assemblages. The proportion of rotated forms decreases from $31.3 \%$ at $\mathrm{KZ} 2$ to $28.5 \%$ at $\mathrm{CN} 3$ and $15.6 \%$ at $\mathrm{CN} 1$.

The proportion of non-clast silcrete core forms is presented in Table 5. Eight different forms are represented across all assemblages, with six forms in the KZ1 and KZ2 assemblages, four in CN1 and two in $\mathrm{CN} 3$. One bipolar core was recorded at $\mathrm{CN1}$, while one flake-blank core was recorded at $\mathrm{KZ1}$ and two at KZ2. One radial core was recorded at both KZ1 and KZ2. Test core forms were also rare, with only one example recorded at KZ1. Two nuclear-tool cores were recorded at KZ2. No microblade cores were recorded in this material.

\begin{tabular}{|lcccc|}
\hline Core Type & CN1 & CN3 & KZ1 & KZ2 \\
\hline Bifacial & $2(20)$ & & $4(36.4)$ & $5(21.7)$ \\
\hline Bipolar & $1(10)$ & & $1(9.1)$ & $2(8.7)$ \\
\hline $\begin{array}{l}\text { Flake blank } \\
\text { Multiple }\end{array}$ & $1(10)$ & $1(20)$ & $2(18.2)$ & $1(4.3)$ \\
\hline $\begin{array}{l}\text { Nuclear tool } \\
\text { Radial }\end{array}$ & & & $1(9.1)$ & $1(4.3)$ \\
\hline Test & $6(60)$ & $4(80)$ & $1(9.1)$ & $12(52.2)$ \\
\hline Unifacial & $10(100)$ & $5(100)$ & $11(100)$ & $23(100)$ \\
\hline Total & & & \\
\hline
\end{tabular}

Table 5. Frequency and proportion of non-clast silcrete core types per assemblage.

Unifacial cores are the single most common non-clast core form in all assemblages except KZ1, varying from $80 \%$ at $\mathrm{CN} 3$, followed by $60 \%$ at $\mathrm{CN} 1,52.2 \%$ at $\mathrm{KZ} 2$ and $18.2 \%$ at $\mathrm{KZ} 1$. At $\mathrm{KZ} 1$ the proportion of bifacial cores is twice that of unifacial cores (36.4\% compared to $18.2 \%$ ) and the combined proportion of rotated core forms is considerably higher than that of unifacial forms at KZ1 (54.6\% compared to $18.2 \%$ ). This pattern does not follow at CN1, CN3 and KZ2. These assemblages show similar patterns to those identified for clast silcrete.

Table 6 presents the proportion of quartz core forms. As in the clast silcrete component, microblade forms are confined to KZ2. Radial cores occur only at CN1, CN3 and KZ1. Bipolar cores are uncommon in all assemblages. Nuclear-tool forms account for less than $5 \%$ of quartz core forms in all of the assemblages. Test core forms are relatively uncommon across all assemblages. The highest proportion of test cores occurs at $\mathrm{CN} 1(8.5 \%)$ and $\mathrm{CN} 3(6.1 \%)$. Unifacial cores are the most common quartz core form in all assemblages, varying from $51.1 \%$ at KZ1 to over $66 \%$ at CN3. Again the proportion of rotated core forms (bifacial and multiple combined) is highest at KZ1 (35.2\%). The low proportion of rotated core forms indicates that extending the life of quartz cores was not a priority.

\begin{tabular}{|lcccc|}
\hline Core Type & CN1 & CN3 & KZ1 & KZ2 \\
\hline Bifacial & $92(18.3)$ & $49(16.7)$ & $37(26.6)$ & $118(28.2)$ \\
\hline Bipolar & $6(1.2)$ & $2(0.7)$ & $6(4.3)$ & $19(4.5)$ \\
\hline Flake blank & $5(1)$ & $8(2.7)$ & $1(0.7)$ & $11(2.6)$ \\
\hline Microblade & & & & $2(0.5)$ \\
\hline
\end{tabular}




\begin{tabular}{|lcccc|}
\hline Core Type & CN1 & CN3 & KZ1 & KZ2 \\
\hline Bifacial & $92(18.3)$ & $49(16.7)$ & $37(26.6)$ & $118(28.2)$ \\
\hline Bipolar & $6(1.2)$ & $2(0.7)$ & $6(4.3)$ & $19(4.5)$ \\
\hline Flake blank & $5(1)$ & $8(2.7)$ & $1(0.7)$ & $11(2.6)$ \\
\hline Microblade & & & & $2(0.5)$ \\
\hline Multiple & $46(9.1)$ & $19(6.5)$ & $12(8.6)$ & $11(2.6)$ \\
\hline Nuclear tool & $19(3.8)$ & $3(1)$ & $6(4.3)$ & $6(1.4)$ \\
Radial & $2(0.4)$ & $1(0.3)$ & $1(0.7)$ & $19(4.5)$ \\
\hline Test & $43(8.5)$ & $18(6.1)$ & $5(3.6)$ & $233(55.6)$ \\
\hline Unifacial & $290(57.7)$ & $194(66)$ & $71(51.1)$ & \\
\hline Total & & & & $419(100)$ \\
\hline
\end{tabular}

Table 6. Frequency and proportion of quartz core types per assemblage.

\section{Minimum number of flakes (MNF) to core ratio}

The MNF to core ratio is the most basic measure of core reduction intensity and is calculated by summing the total number of flakes with a platform (complete and proximal flakes), together with half the longitudinal splits (Holdaway and Stern 2004). As core reduction proceeds, the number of flakes produced increases relative to the number of cores (Dibble 1995). Longer occupation by less mobile groups will limit opportunities to replenish raw material stocks and result in more complete reduction of cores and the increased production of flakes.

Plotting the ratio for each raw material type (Table 7) indicates both similarities and differences among the assemblages. In all of the assemblages the ratio for quartz is lowest, indicating that this local material was the least intensively reduced. The quartz ratio also shows the least variability between assemblages. KZ2 has the highest ratio with eight and CN1 the lowest with 7.1, while the ratio is 7.3 for both CN3 and KZ1.

\begin{tabular}{|lcccc|}
\hline Material & CN1 & CN3 & KZ1 & KZ2 \\
\hline Clast & 20.8 & 17.5 & 16.5 & 18.3 \\
\hline Non-clast & 23.7 & 21 & 14.5 & 25.4 \\
\hline Quartz & 7.1 & 7.3 & 7.3 & 8 \\
\hline
\end{tabular}

Table 7. MNF (minimum number of flakes) to core ratio per raw material and assemblage.

The ratio for clast silcrete is lower than that for non-clast silcrete in each of the assemblages except KZ1. The CN1 assemblage has the highest ratio for clast silcrete, followed by KZ2, CN3 and KZ1. The higher ratio at $\mathrm{CN} 1$ and the lower ratio at KZ1 are consistent with a distance-decay relationship, but this is not the case for either the KZ2 or CN3 assemblages. The ratios for non-clast silcrete demonstrate a greater amount of variability between the assemblages than those for clast silcrete and quartz. KZ2 has the highest ratio for non-clast silcrete, followed by $\mathrm{CN} 1$ and $\mathrm{CN} 3$.

None of the assemblages demonstrate a clear pattern of intensive core reduction in all of the raw material categories. KZ1 has the lowest value for clast and non-clast silcrete and the second lowest for quartz, suggesting that reduction was less intensive relative to the other assemblages. This may reflect the closer proximity of KZ1 to major clast silcrete sources than is true for the other assemblages. Both CN1 and KZ2 have the highest ratios for clast and non-clast silcrete, indicating that silcrete core reduction was 
most intensive in these assemblages. In addition, KZ2 has the highest ratio for quartz. CN3 exhibits more intensive core reduction than KZ1, but this is not as intensive as either CN1 or KZ2. The implication of the overall patterning in MNF to core ratios is that KZ2 saw the longest occupation of the four assemblages.

\section{Non-cortical flake to cortical flake ratio}

Increased core reduction also leads to a decrease in the proportion of cortical surfaces on flakes and cores (Dibble 1995). The MNF to core ratios suggested that non-clast silcrete was generally the most intensively worked material. Thus it is expected that the non-cortical to cortical complete flake ratio will be highest for this material. Results for this ratio (Table 8) indicate that this is not the case, but rather the ratio is highest for clast silcrete across all the assemblages.

\begin{tabular}{|lllll}
\hline Material & CN1 & CN3 & KZ1 & KZ2 \\
\hline Clast & 12.3 & 11.7 & 9 & 8.6 \\
\hline Non-clast & 9.9 & 11.2 & 8.1 & 7.6 \\
Quartz & 0.8 & 0.2 & 1.4 & 1
\end{tabular}

Table 8. Non-cortical to cortical complete flake ratio per raw material and assemblage.

Non-clast silcrete has the second highest ratio, followed by quartz. The ratio is consistent for quartz in the four assemblages and points to the reduction of local cortical nodules. The same cannot be said for clast silcrete. Clearly clast silcrete, although available within the wider area, was not utilised in the same way as local quartz and was less likely to be available as fist-sized gibber nodules. Clast silcrete nodules were transported to the locations as partially decortified cores. This is further supported by the relative proportion of cortical complete flakes to non-cortical complete flakes (Tables 9-11). Quartz exhibits a pattern different from both the silcretes. Cortical complete flakes are common and a large proportion of the flakes have greater than 50 percent cortex. This indicates on-site reduction of cortical nodules.

\begin{tabular}{|lrrrr|}
\hline Cortex Category & \multicolumn{1}{c}{ CN1 } & \multicolumn{1}{c}{ CN3 } & KZ1 & KZ2 \\
\hline None & $431(92.5)$ & $258(92.1)$ & $358(89.9)$ & $1336(89.5)$ \\
\hline $1-50 \%$ & $19(4.1)$ & $15(5.4)$ & $31(7.8)$ & $104(7)$ \\
\hline $50-99 \%$ & $13(2.8)$ & $6(2.1)$ & $9(2.3)$ & $50(3.4)$ \\
\hline Complete & $3(0.6)$ & $1(0.4)$ & $0(0)$ & $2(0.1)$ \\
Total & $466(100)$ & $280(100)$ & $398(100)$ & $1492(100)$ \\
\hline
\end{tabular}

Table 9. Frequency and percentage (in parentheses) of clast silcrete complete flakes with different amounts of cortex.

\begin{tabular}{|lcccr|}
\hline Cortex Category & CN1 & CN3 & KZ1 & \multicolumn{1}{c|}{ KZ2 } \\
\hline None & $139(90.8)$ & $67(91.8)$ & $89(89)$ & $189(88.3)$ \\
\hline $1-50 \%$ & $12(7.8)$ & $3(4.1)$ & $6(6)$ & $18(8.4)$ \\
\hline $50-99 \%$ & $2(1.3)$ & $3(4.1)$ & $5(5)$ & $6(2.8)$ \\
Complete & $0(0)$ & $0(0)$ & $0(0)$ & $1(0.5)$ \\
Total & $153(100)$ & $73(100)$ & $100(100)$ & $214(100)$ \\
\hline
\end{tabular}

Table 10. Frequency and percentage (in parentheses) of non-clast silcrete complete flakes with different amounts of cortex. 


\begin{tabular}{|lcccc|}
\hline Cortex Category & CN1 & CN3 & KZ1 & KZ2 \\
\hline None & $1212(44.6)$ & $698(41.3)$ & $413(58)$ & $1222(50.4)$ \\
\hline $1-50 \%$ & $823(30.3)$ & $572(33.9)$ & $189(26.5)$ & $815(33.6)$ \\
\hline $50-99 \%$ & $537(19.7)$ & $329(19.5)$ & $97(13.6)$ & $321(13.2)$ \\
\hline Complete & $147(5.4)$ & $90(5.3)$ & $13(1.8)$ & $66(2.7)$ \\
\hline Total & $2719(100)$ & $1689(100)$ & $712(100)$ & $2424(100)$ \\
\hline
\end{tabular}

Table 11. Frequency and percentage (in parentheses) of quartz complete flakes with different amounts of cortex.

The KZ1 and KZ2 ratios for quartz are higher than the ratios for $\mathrm{CN} 1$ and $\mathrm{CN} 3$, suggesting more intensive reduction of quartz cores in the $\mathrm{KZ}$ assemblages, a result supported by the MNF to core ratio for KZ2, but not KZ1. The patterns emerging at KZ2 and to a lesser extent KZ1 cannot be attributed to differential raw material access because both locations are the same distance from the nearest silcrete sources. CN1 and CN3 show similar values for both types of silcrete. This result supports the relatively high values of the MNF to core ratio and suggests that silcrete reduction was intensive in these two assemblages. KZ1 and KZ2 have similar results for both types of silcrete. This result is surprising because the MNF to core ratio suggested that core reduction was more intensive at KZ2 than KZ1.

\section{Non-cortical core to cortical core ratio}

The non-cortical to cortical core ratio provides another measure of core reduction intensity. Values for this ratio by assemblage and raw material are presented in Table 12. Clast silcrete has the highest ratio for each of the assemblages, followed by non-clast silcrete, except for $\mathrm{CN} 3$, where no cores with cortex were recorded. Quartz has the lowest ratio in all the assemblages, with the ratio not exceeding one, indicating that there are more cortical than non-cortical cores.

\begin{tabular}{|lllll}
\hline Material & CN1 & CN3 & KZ1 & KZ2 \\
\hline Clast & & & & 2.1 \\
\hline Non-clast & 2.6 & 3.2 & 3.7 & 1.3 \\
Quartz & 1.5 & 0 & 2.7 & 0.3 \\
\hline
\end{tabular}

Table 12. Non-cortical to cortical core ratio per raw material and assemblage.

The highest ratios for the three raw material types all occur in the KZ1 assemblage. This is unexpected because the MNF to core and the non-cortical flake to cortical flake ratios suggested that KZ1 cores are the least intensively worked, but it does fit with the high proportion of rotated core forms at KZ1, which suggest a greater likelihood of cortex removal resulting from the flaking of multiple surfaces. The results for the $\mathrm{CN} 1$ and KZ2 assemblages are also ambiguous. The MNF to core and the non-cortical to cortical complete flake ratios suggested that core reduction was intensive at CN1. This is not supported by the non-cortical to cortical core ratio, which indicates a low proportion of decortified cores at CN1. There is a similar result for KZ2, but the pattern is less clear. The MNF to core ratio was high at KZ2, but the non-cortical to cortical complete flake ratio low. The low proportion of decortified cores at KZ2 supports the non-cortical to cortical complete flake ratio, but is in disagreement with the MNF to core ratio. $\mathrm{CN} 3$ follows a pattern consistent with the non-cortical to cortical complete flake ratio. 


\section{Unmodified flake to tool ratio}

The unmodified flake to tool ratio is the simplest measure of tool production. Low values for this ratio indicate that proportionally more flakes in an assemblage are modified into tools. Proportionally fewer quartz flakes are modified into tools in the $\mathrm{CN1}, \mathrm{CN} 3$ and $\mathrm{KZ2}$ assemblages compared to both types of silcrete (Table 13). The KZ1 assemblage is an exception. Here the ratio for quartz is less than that for most clast silcrete components. The ratio in all assemblages is lowest for non-clast silcrete indicating that there are fewer unretouched flakes relative to retouched flakes on this material than in any other material. Nonclast silcrete appears to have been favoured for tool production.

\begin{tabular}{|lcccc|}
\hline Material & CN1 & CN3 & KZ1 & KZ2 \\
\hline Clast & 8.3 & 10.5 & 11.7 & 13 \\
\hline Non-clast & 3.8 & 2.8 & 4.3 & 3.9 \\
\hline Quartz & 13.9 & 18 & 9.5 & 19.9 \\
\hline
\end{tabular}

Table 13. Flake to MNT (minimum number of tools) ratio per raw material and assemblage.

In general, tool production is least intensive at KZ2. The ratio for clast silcrete and quartz at KZ2 is the highest of the assemblages; the value for non-clast silcrete is the second highest behind KZ1. The $\mathrm{CN} 1$ and CN3 assemblages have the lowest values for both types of silcrete, but there is only a marginal difference between the non-clast value at $\mathrm{CN} 1$ and KZ2. Additionally, there is no clear pattern between the silcretes in the $\mathrm{CN} 1$ and $\mathrm{CN} 3$ assemblages, with the value for clast lowest at $\mathrm{CN} 1$ and the value for non-clast lowest at $\mathrm{CN} 3$. For quartz, the value at $\mathrm{CN} 1$ and $\mathrm{CN} 3$ is much higher than that at KZ1.

\section{Discussion}

As with much of the archaeological record of western NSW, the surface archaeological distributions across Pine Point and Langwell Stations cannot be interpreted as ethnographic slices of time. Instead, they represent a time-averaged (Stern 1994) record of archaeological deposition and geomorphic process. Interpretations should take account of the time-accumulative nature of the record. The radiocarbon chronology from the heat-retainer hearths indicates multiple episodes of occupation during the last 2000 years. Further, inconsistencies in the technological indices point to the variable nature of assemblage formation. Some of these inconsistencies may reflect the variable forms in which the raw materials are available as well as the variable nature of the behavioural processes responsible for assemblage accumulation. These behaviours may include artefact recycling, and artefact removal as well as variable occupation spans. This will be further discussed below.

Consistent patterns of reduction intensity for both types of silcrete are difficult to identify in the assemblages. In all four assemblages the non-cortical to cortical complete flake and the non-cortical to cortical core ratios are highest for clast silcrete rather than non-clast silcrete. These results do not follow the MNF to core ratio that generally suggested non-clast cores were the most intensively worked. The MNF to core and the non-cortical to cortical complete flake ratios suggest that core reduction is most intensive in the CN1 and KZ2 assemblages, but this is not supported by the non-cortical to cortical core ratio. From this it is difficult to draw straightforward conclusions about the intensity of clast and nonclast silcrete core reduction. Instead, the variability hints at the complex nature of assemblage formation, and suggests that the Pine Point/Langwell assemblages do not represent a single process of silcrete acquisition and reduction through time. Rather, the assemblages represent multiple raw material management processes. The re-occupation of the four locations through time also raises the possibility 
that at least some of the artefacts were reused on numerous occasions. The implication of this is that not only were many of the artefacts, and especially those made of either type of silcrete, manufactured elsewhere, but also they may have experienced multiple episodes of reduction and use through time at the locations.

The reduction of quartz across the assemblages shows far greater consistency compared to either of the silcretes. Quartz cores are the least rotated, indicating reduction from predominantly one platform surface. Further, the MNF to core ratio suggest that quartz is the least intensively worked material, and the non-cortical to cortical complete flake and the non-cortical to cortical core ratio support this. Quartz is also generally the least intensively utilised material for the production of tools. This consistency suggests a more limited set of behaviours are represented in the acquisition and reduction of quartz compared to the silcretes. Quartz is a local raw material to all of the assemblages and occurs as fist-sized rounded cobbles on valley slopes and creek beds. The size and form of the nodules may also constrain the reduction of quartz thus producing a more uniform pattern than the two types of silcrete.

At least some aspects of variability among the assemblages reflect differential access to raw materials. For example, the non-intensive reduction of quartz reflects to some degree the abundant sources of this material within the immediate vicinity of the assemblages. Measures of silcrete reduction are full of inconsistencies: while there are some aspects of a distance-decay relationship, assemblages located furthest from possible silcrete sources do not demonstrate a clear pattern of more intensive reduction. This may be interpreted in a number of ways: silcrete was not always transported to the locations from the closest sources, each location has variable occupation histories, and a single place was rarely used the same way through time.

The surface archaeological record of Pine Point/Langwell was investigated as a series of places with individual use histories. These were revealed through the investigation of assemblage formation over a 2000 year period of occupation which was indicated by the radiocarbon ages from 16 heat-retainer hearths. While this is not a definitive chronological record, it provides a good chronological framework consistent with other hearth dating programmes across western NSW (e.g. Holdaway et al. 2002, 2005). The results of this analysis reveal both variability and consistency in assemblage composition across a relatively small area of the landscape. While some aspects represent responses to the distribution and form of lithic raw material sources, others are indicative of variability in the intensity of occupation over the long-term. Different locations exhibited varied occupational signatures. For instance, measures of raw material utilisation suggest that occupation intensity at KZ1 and CN3 was less intensive than at KZ2 and CN1.

The Pine Point/Langwell locations can be regarded as persistent places in the sense that they document multiple episodes of occupation over the last 2000 years. Although it is not possible to link any single artefact with a specific period of occupation as indicated by the radiocarbon chronology, the presence of hearths with multiple age determinations within each of the artefact assemblages, and around the broader Pine Creek-Rantyga Creek confluence indicate multiple visits. Within this context artefact discard would also have occurred on multiple occasions, and some of this may have coincided with the occupational episodes represented by the hearths. The boundaries of these occupations and the exact reasons behind the reuse of the four locations can never be known. In any case, these are likely to be many and complex. What we do know is that the Pine Creek-Rantyga Creek confluence was the focus of repeated occupation. As applied by Shiner et al. (2005) in relation to assemblages from Burkes Cave, Fowlers Gap (SC and ND locations) and Stud Creek, the analysis of stone artefact assemblage composition within temporal and economic frameworks is one method of assessing the persistence of occupation within palimpsest deposits. 


\section{Conclusion}

Analysis of the composition of the Pine Point/Langwell assemblages indicates both consistencies and inconsistencies in the reduction and utilisation of lithic raw materials. Some of these consistencies are argued to reflect the character and distribution of the wider lithic landscape. In general, there is a distance-decay relationship in the reduction of silcrete. This relationship is not evident in all measures of reduction intensity. Variation in measures of core reduction is interpreted to reflect the variable nature of occupation through time at each of the locations in both duration and frequency. Over the time span represented in the Pine Point/Langwell occupational chronology, multiple behavioural patterns resulted in internal assemblage variability. These patterns are consistent with persistent but varied use of the locations during the last 2000 years.

The variable patterns identified in the Pine Point/Langwell assemblages raise some interesting questions about interpretative scales. Depending upon the perspective adopted, the Pine Point/Langwell assemblages may represent either accumulation over too long a timescale or over too short a timescale. Those seeking ethnographic-scale interpretations would argue that the Pine Point/Langwell assemblages are coarse grained with few clear behaviours represented. Others, who are interested in clear average patterns of assemblage composition representative of the dominant types of behaviour, may contend that the assemblages do not represent enough accumulation through time, hence variable and inconsistent intra-assemblage patterns. Viewed as persistent places that were utilised on multiple occasions during the last 2000 years, the Pine Point/Langwell assemblages point to the complex and varied processes responsible for the formation of the archaeological assemblages we define in the present.

\section{Acknowledgements}

Thank you to Andrew Fairbairn and Sue O'Connor for the opportunity to publish this paper in the Archaeometry volume. I wish to acknowledge the assistance of Simon Holdaway, Patricia Fanning and Peter Sheppard in supporting my research. The Broken Hill Local Aboriginal Land Council supported the project and consented to the excavation of the heat-retainer hearths. In particular I thank Raymond O'Donnell. Lisa Shiner and Bridget Mosley assisted during the 2002 field season. This work was funded by a University of Auckland Doctoral Scholarship, an AIATSIS grant, and a University of Waikato Radiocarbon Dating Laboratory grant. The Harvy family of Pine Point and the Harrison family of Langwell allowed me to undertake research on their properties. I also thank Val Attenbrow and two anonymous referees for their helpful comments. 


\section{References}

Bamforth, D. B. and M. S. Becker. 2000. Core/biface ratios, mobility, refitting, and artifact use-lives: A Paleoindian example. Plains Anthropologist 45(173):273-90.

Cane, S. 1984. Desert camps: A case study of stone artefacts and behaviour in the Western Desert. Unpublished PhD thesis, Department of Prehistory, Australian National University.

Dibble, H. L. 1988. Typological aspects of reduction and intensity of utilization of lithic resources in the French Mousterian. In H. L. Dibble and A. Montet-White (eds), Upper Pleistocene prehistory of Western Eurasia, pp 181-97. Philadelphia: University of Pennsylvania Museum.

Dibble, H. L. 1995. Raw material availability, intensity of utilization, and Middle Paleolithic assemblage variability. In H. Dibble and M. Lenoir (eds), The Middle Paleolithic site of Combe-Capelle Bas (France), pp 289-315. Philadelphia: University of Pennsylvania Museum.

Dibble, H. L. and N. Rolland. 1992. On assemblage variability in the Middle Paleolithic of Western Europe: History, perspectives, and a new synthesis. In H. L. Dibble and P. Mellars (eds), The Middle Paleolithic: Adaptation, behavior and variability, pp 1-25. Philadelphia: University of Pennsylvania Museum.

Dibble, H. L., B. Roth and M. Lenoir. 1995. The use of raw materials at Combe-Capelle Bas. In H. Dibble and M. Lenoir (eds), The Middle Paleolithic Site of Combe-Capelle Bas (France), pp.259-287. Philadelphia: University of Pennsylvania Museum.

Ebert, J, I. 1992. Distributional archaeology. Albuquerque: University of New Mexico Press.

Elston, R. E. 1990. A cost-benefit model of lithic assemblage variability. In R. G. Elston and E. E. Bundy (eds), The archaeology of James Creek Shelter, pp 153-164. Salt Lake City: University of Utah Anthropological Papers 115.

Fanning, P. 2002. Beyond the Divide: A new geoarchaeology of Aboriginal stone artefact scatters in Western NSW, Australia. Unpublished PhD thesis, Macquarie University.

Fletcher, R. 1995. The Limits of settlement growth, a theoretical outline. Cambridge: Cambridge University Press.

Gould, R. A. 1980. Living archaeology. Cambridge: Cambridge University Press.

Hayden, B. 1979. Palaeolithic reflections: Lithic technology and ethnographic excavations among Australian Aborigines. Canberra: Australian Institute of Aboriginal Studies.

Holdaway, S., D. Witter, P. Fanning, R. Musgrave, G. Cochrane, T. Doelman, S. Greenwood, D. Pigdon and J. Reeves. 1998. New approaches to open site spatial archaeology in Sturt National Park, New South Wales, Australia. Archaeology in Oceania 33:1-19.

Holdaway, S., P. C. Fanning and D. C. Witter. 2000. Prehistoric Aboriginal occupation of the rangelands: Interpreting the surface archaeological record of Far Western New South Wales. Rangelands Journal 22(1):44-57.

Holdaway, S. J., P. C. Fanning, M. Jones, J. Shiner, D. C. Witter and G. Nicholls. 2002. Variability in the chronology of Late Holocene Aboriginal occupation on the arid margin of Southeastern Australia. Journal of Archaeological Science 29:351-363.

Holdaway, S. J., J. Shiner and P. Fanning. 2004. Hunter-gathers and the archaeology of the long-term: An analysis of surface stone artefacts from Sturt National Park, Western New South Wales, Australia. Asian Perspectives 43:34-72.

Holdaway, S and N. Stern. 2004. A record in stone: The study of Australia's flaked stone artefacts. Canberra: Museum Victoria and Aboriginal Studies Press, Australia Institute of Aboriginal and Torres Strait Islander Studies.

Holdaway, S. J., P. Fanning and J. Shiner. 2005. Absence of evidence or evidence of absence? Understanding the chronology of indigenous occupation of western New South Wales, Australia. Archaeology in Oceania 40(2):33-49.

Schlanger, S. H. 1992. Recognising persistent places in Anasazi settlement systems. In J. Rossignol and L. Wandsnider (eds), Space, time and archaeological landscapes, pp 91-112. New York: Plenum Press. 
Shiner, J. I. 2004. Place as occupational histories: Towards an understanding of deflated surface artefact distributions in the West Darling, New South Wales, Australia. Unpublished PhD thesis, The University of Auckland.

Shiner, J. I. 2006. Artefact discard and accumulated patterns in stone artefact assemblage composition in surface archaeological deposits from Pine Point and Langwell Stations, western New South Wales. The Rangeland Journal 28(2):183-195.

Shiner, J., S. Holdaway, H. Allen and P. Fanning. 2005. Stone artefact assemblage variability in Late Holocene contexts in Western New South Wales: Burkes Cave, Stud Creek and Fowlers Gap. In C. Clarkson and L. Lamb (eds), Lithics 'Down Under': Australian Perspectives on Lithic Reduction, Use and Classification, pp 67-80. Oxford: Archaeopress.

Shott, M. J. 1989. On tool-class use lives and the formation of archaeological assemblages. American Antiquity 54(1):9-30.

Shott, M. J. 1995. How much is a scraper? Curation, use rates, and the formation of scraper assemblages. Lithic Technology 20(1):53-72.

Stern, N. 1994. The implications of time-averaging for reconstructing the land-use patterns of early toolusing Hominids. Journal of Human Evolution 27:89-105.

Thomas, D. H. 1975. Nonsite sampling in archaeology: Up the creek without a site? In J. W. Mueller (ed.), Sampling in archaeology, pp 61-81. Tucson: University of Arizona Press.

Veth, P. M. 1993. Islands in the interior: The dynamics of prehistoric adaptations within the Arid Zone of Australia. Ann Arbor: International Monographs in Prehistory.

Waters, M. R. and D. D. Kuehn. 1996. The geoarchaeology of place: The effect of geological processes on the preservation and interpretation of the archaeological record. American Antiquity 61(3): 483-497

Witter, D. 1992. Regions and resources. Unpublished PhD thesis, Department of Prehistory, Australian National University. 